\title{
Harmful Algal Blooms and their Assessment in Fjords and Coastal Embayments
}

BY ALLAN D. CEMBELLA, DIEGO A. IBARRA, JORGE DIOGENE, AND EINAR DAHL

\section{EMBAYMENT SYSTEMS}

Coastal embayments are a broad category of an ecosystem type that may be loosely defined as an enclosed or semienclosed aquatic environment along a land-mass margin. Embayments are highly diverse, representing a spectrum of varying degrees of physical isolation from the open coast and hydrodynamic regime. Such systems include certain estuaries, lagoons, rías ("drowned estuaries"), firths, and fjords. At one extreme of the continuum, classic fjords, such as are found in Norway, Chile, and British Columbia, are typically deeply glaciated basins (often $\mathrm{V}$-shaped) with steep sides, and are generally restricted to latitudes above $45^{\circ}$ in both hemispheres. Fjordal water circulation patterns are characterized by surface outflow of buoyant freshwater, and an inward-bound compensation current, so-called estuarine circulation. Bottom water of fjords often tends to become anoxic, especially with the presence of a sill formed by excavated or scoured material accumulated towards the mouth of the inlet (Skjoldal et al., 1995) (Figure 1). By contrast, coastal lagoons, such as those found along the Mediterranean Sea (right), the Carolinas in the United States, and other parts of the Iberian coast, as well as in the tropics, are often shallow basins linked to the land's margin, but lack the stratification parameters and circulation of fjords, and typically have a soft-bottom substrate.
The diversity of these embayments defies a common description; but because these systems are partially surrounded by land and are transitional zones, they tend to be heavily affected by terriginous run-off, sediment transport, and other land-sea interactions (Valiela, 1991). It may be argued that because of the geomorphological and hydrographic diversity among coastal embayments, meaningful comparisons cannot be made. Nevertheless, it seems reasonable to begin the process of sub-categorization of the different types of coastal embayments with respect to determining how basin morphology and degree of retention of water and organisms affects the dynamics of key harmful algal bloom (HAB) species. Such ecosystems do share common features related to spatial scale, constrained hydrodynamics, and land-sea interactions that can be clearly distinguished from processes in large-scale coastal current or upwelling zones, even though embayments may be linked to these adjacent systems.

The hydrographic regime within coastal embayments is complex (hence, difficult to model) and may include estuarine circulation, formation of fronts and internal waves, geostrophic adjustment, wind and tidal mixing, vertical density gradients, and the influence of Earth's rotation (Coriolis effect). In turn, circulation is coupled to events in adjacent coastal waters. In the open ocean, mesoscale eddies (spatial 
scale of $100 \mathrm{~km}$ and a temporal scale of one month) are dominant features of variability. Within coastal embayments, physical factors such as winds, tides, flux of water and dissolved and particulate material, as well as related extreme events (e.g., flooding, storm surges) often dominate on a temporal scale of hours to days and at a spatial scale of $10 \mathrm{~m}$ to $10 \mathrm{~km}$. In stratified waters, the scale of these processes is normally on the order of the internal Rossby radius of deformation (ca. $10 \mathrm{~km}$ ). Physical constraints imposed by fixed land boundaries and the bathymetry of embayments dictate the heightened importance of small-scale processes in defining water circulation within these systems.

\section{HARMFUL ALGAL BLOOMS IN COASTAL EMBAYMENTS}

HABs are predominantly coastal phenomena, and with the exception of toxic blooms of certain cyanobacteria ("bluegreen algae"), their harmful effects are most often manifest upon coastal biota (GEOHAB, 2001). Much of the global production of seafood and exploitation of fish and shellfish resources, as well as

\section{Allan D. Cembella (acembella@awi-} bremerhaven.de) is Head of Biosciences and AWI Speaker for the Coastal Research Programme, Alfred Wegener Institute for Polar and Marine Research, Bremerhaven, Germany. Diego A. Ibarra is Ph.D. Candidate, Department of Oceanography, Dalhousie University, Halifax, Nova Scotia, Canada. Jorge Diogene is Research Scientist, Institut de Recerca i Technologia Agroalimentaries, Centre d'Aqüicultura, Sant Carles de la Rápita, Tarragona, Spain. Einar Dahl is Head of Research Group, Coastal Zone Ecosystems, Institute for Marine Research, Flødevigen Marine Research Station, His, Norway. mariculture activity, is situated within the coastal zone. HABs are, therefore, of critical importance to coastal-zone management of marine resources.

Coastal embayments are often zones of high primary productivity and biodiversity, and are strategically important as spawning areas, refuges, and nurseries for secondary production, sustaining key populations of fish and benthic invertebrates (Valiela, 1991). Yet, embayments are particularly vulnerable to anthropogenic changes in the biological and chemical regime, including the introduction of exotic species via deballasting of ships or transfer of aquaculture stock.

Although large-scale catastrophic effects on ecosystem function caused by HABs are rare and usually transient, there are some notable exceptions. For example, massive "brown tides" of the picoplanker Aureococcus in embayments in eastern Long Island, New York in the late 1980s devastated eel grass beds by reducing light penetration, causing loss of refuge for bay scallops, and other disruptive and long-lasting consequences for benthic habitats (Cosper et al., 1989). In Scandinavia, the 1988 bloom of a fish-killing flagellate Chrysochromulina covered a maximal area of $75,000 \mathrm{~km}^{2}$ of the Skagerrak and Kattegat and caused widespread ecosystem damage (Edvardsen and Paasche, 1998). Mass mortalities of a wide range of marine organisms, such as wild and farmed fish, mollusks, sea stars, jellyfish, sponges, and red algae were observed, particularly in fjords and other embayments.

Coastal embayments receive direct and often disruptive loading of dissolved and particulate material from the land, including nutrients, suspended material, dissolved organics, and metals from both natural and anthropogenic sources. All of these inputs can affect HAB dynamics; because effects are concentration-dependent, they are likely to be more obvious and dramatic than those in open coastal and oceanic environments. Changes in $\mathrm{HAB}$ dynamics and distribution may be more easily tracked in fjords and coastal embayments because of the relative ease of deployment and maintenance of observational technology yielding measurements at appropriate temporal and spatial scales.

Nutrient loading is an influx of nutrients in excess of efflux, and because the geomorphological and hydrographic constraints in embayments tend to restrict dilution, such systems are particularly susceptible to eutrophication (Glibert et al., 1995). This, in turn, can have important consequences with respect to a shift in phytoplankton species dominance, destabilization of successional processes, and promotion of high biomass of harmful algal blooms of certain susceptible species (Riegman, 1998). While acknowledging that nutrients are essential for HAB development, and that nutrient supply ratios may be critical in determining outcomes of inter-specific competition under some circumstances, it does not necessarily follow that eutrophication is generally responsible for the initiation and development HABs in coastal embayments. In fact, evidence is often to the contrary-many harmful blooms, particularly those associated with shellfish toxicity at low biomass and cell concentrations, are clearly not associated with eutrophication. Comparative studies of HAB dynamics in fjords and coastal embayments, as advocated in the GEOHAB (2001) program, contrasting bloom dynamics in eutrophic versus non-eutrophic systems of similar spatial scale and retention characteristics, are 


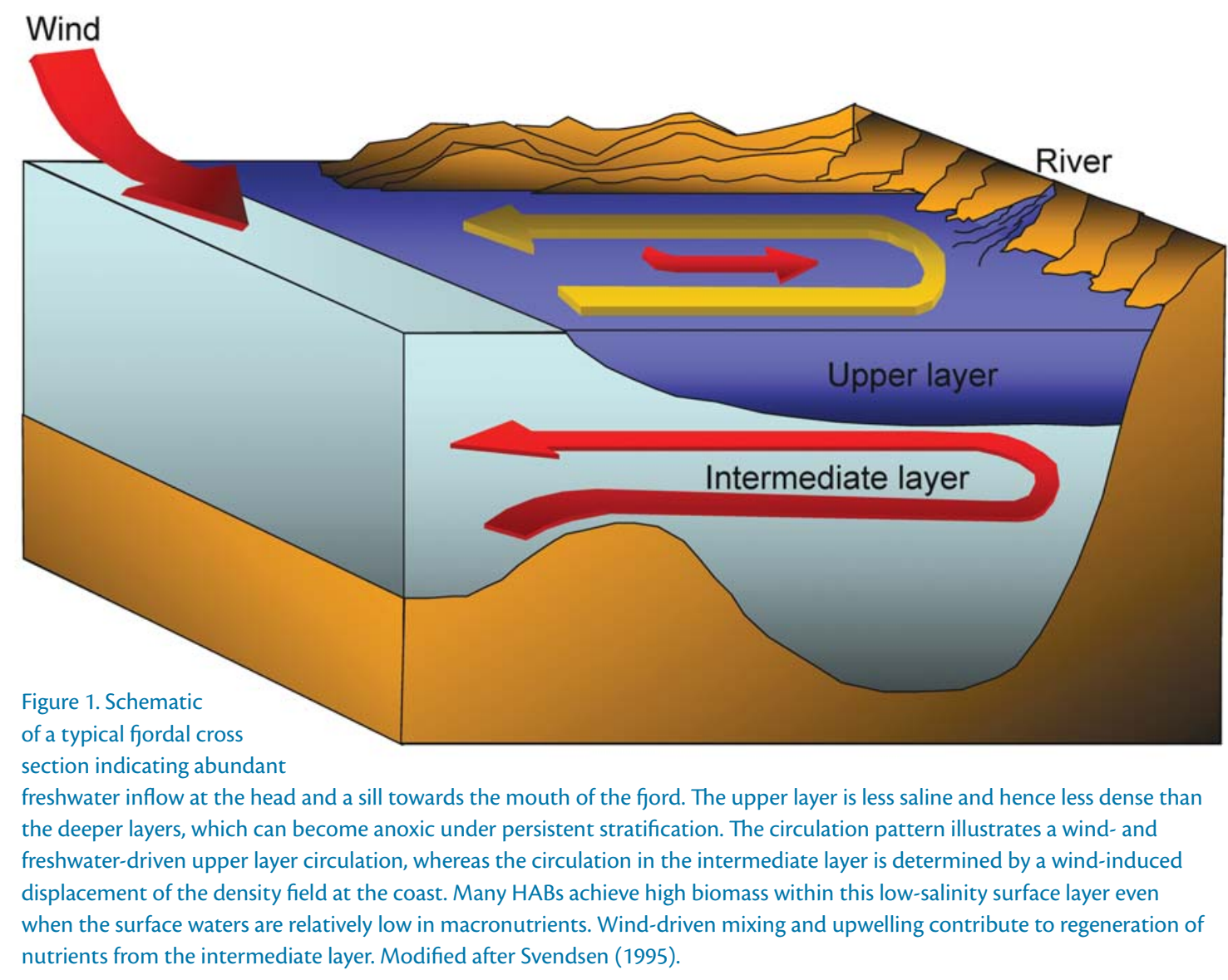

therefore essential to establishing the relative importance of nutrient loading as a driver of bloom formation and development among various species.

Changes in the coastal zone that may be associated with the introduction and development of harmful algal events are particularly crucial to increased use of coastal embayments for aquaculture of fish and shellfish (Hargrave, 1991). Increased deployment of fish farms within coastal embayments and fjords has led to concern about localized eutrophication from excess nutrients and organic matter via fish gills, feces, and unconsumed fish pellets. About 60 percent of the nitrogen from farmed fish is set free via the gills as ammonium and is thus directly available to primary production, whereas phosphorus nutrients tend to adhere to particles and sink to the bottom and are more slowly released to the water col- umn. Such a shift in nutrient loading could increase local primary production and shift phytoplankton species composition, perhaps favoring certain $\mathrm{HAB}$ species. High stocking densities of aquacultured shellfish have the potential for localized depletion of phytoplankton, perhaps causing a shift in the size- or species-spectrum of the phytoplankton (Figure 2). Such effects are largely mitigated within embayments where the flushing rates are high and the residence time is short enough for dispersal of organic wastes and replenishment of phytoplankton. In any case, detailed studies of aquaculture impacts have generally not yielded conclusive evidence for promotion of HABs.

In temperate latitudes, the coastal spring bloom of centric diatoms is commonly followed by a phytoplankton community dominated by large dino- flagellates, then often succeeded by heterotrophic flagellates, microflagellates, and other protistan and metazoan detritivores. The transient discontinuity in normal succession of coastal phytoplankton caused by HABs is interesting in itself, but comparison of the phenomenon among coastal embayments of similar bathymetry, hydrodynamics, and chemical-biological regime is perhaps more instructive.

HABs are exceptional in that they represent a departure from the main sequence of algal blooms, with respect to biomass dominance, tendency towards monospecificity, unpredictability, and/or deleterious ecological consequences. Although the term "harmful algal bloom" is often used to refer only to high-biomass events, a less-restrictive definition applies as well to events where the harmful species is present only in low cell 
numbers or as a minor component of the total algal biomass, even where the harmful alga colonizes surfaces (as is the case for many toxic benthic dinoflagellates).

Phytoplankton species composition and successional processes in coastal embayments are often similar to those occurring along adjacent open coasts, but the temporal phasing and magnitude of the plankton blooms in coastal embayments may differ from those along open coasts, by being delayed and/or spatially condensed. For example, Figure 3 shows the accumulation of the toxic dinoflagellate Dinophysis in dense alongshore bands in a sheltered bay in Norway.
Onshore currents causing downwelling, combined with positive phototaxis by the algae to compensate for downward transport, appear to have produced the "red tide," forming condensed bands of reddish pigmented cells.

Coastal embayments are physically complex systems, and thus pose a challenge for the modeling and prediction of HAB dynamics. Nevertheless, the degree of isolation from the adjacent open coast offers the opportunity for comparison among embayments of the effects of limited flux of water and materials. Furthermore, the delimited geographical extent of such systems permits study of $\mathrm{HAB}$ phenomena at the appropriate tempo- ral and spatial scale, even with limited oceanographic resources for ships and equipment. All of the known adaptive strategies and behaviors of encystment/excystment, layer formation, high biomass generation, vertical migration, heterotrophy, and toxin expression are found among HAB taxa that bloom in these ecosystems.

In spite of the hydrographic and geomorphological diversity among coastal embayments, they share common, although not exclusive, features as retention zones and thus as potential sites for bloom initiation ("seed beds") (Anderson, 1998). While there are also offshore retention zones, such as fronts and ed-

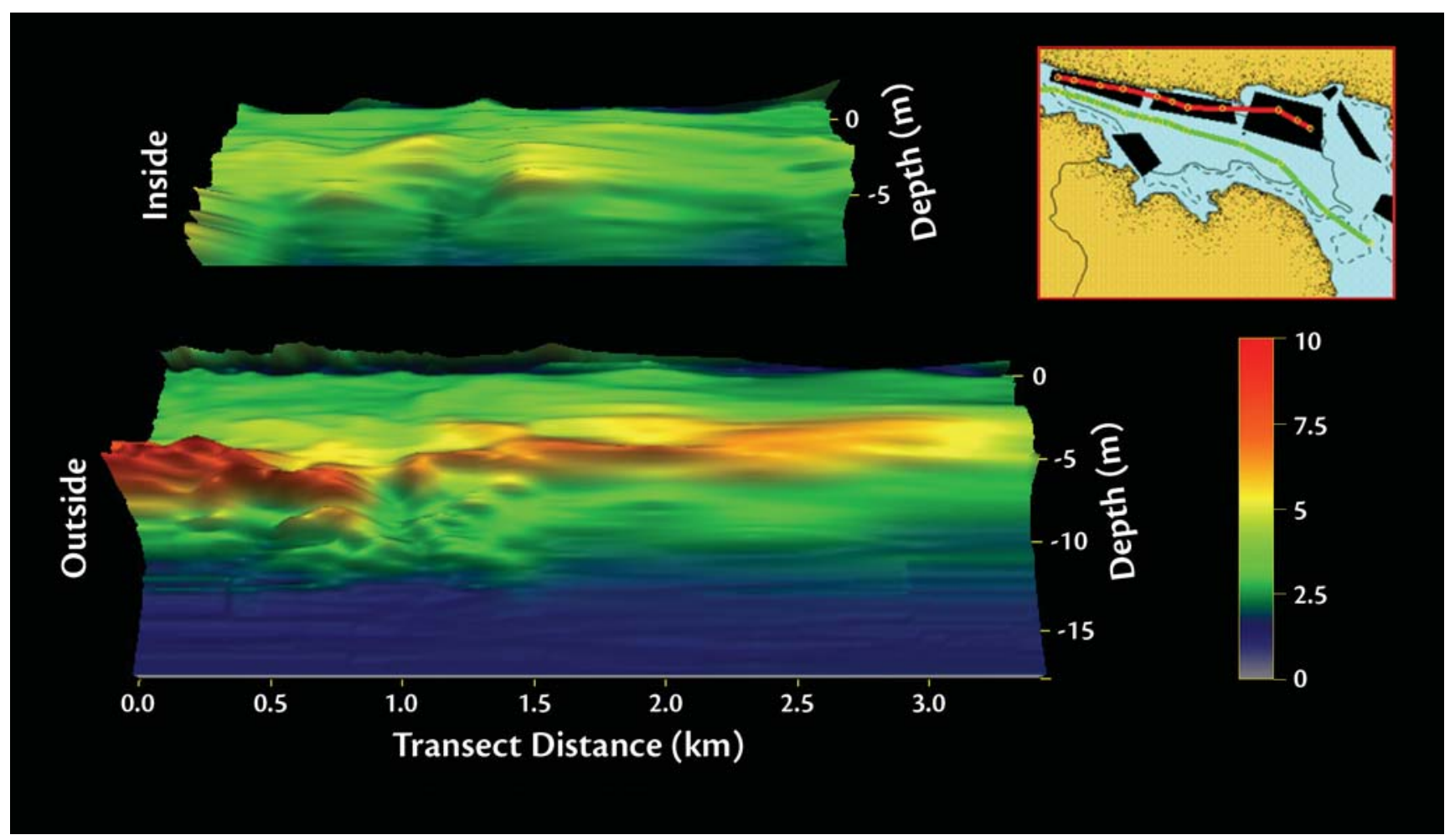

Figure 2. Two-dimensional structure of in situ stimulated chlorophyll fluorescence from multiple casts of a SPMR Satlantic profiler over two transects in Ship Harbour, Nova Scotia, Canada (August 2004). Outside the mussel farm (lower panel), a strong fluorescence layer at mid-depth can be observed, while inside the mussel farm (upper panel), the fluorescence layer is much weaker; presumably this is because the mussels depleted phytoplankton from the layer. This illustrates the importance of depth-integrated or depth-resolved measurements, as opposed to sampling only at a single depth, for detection of HABs in coastal embayments and for early warning of blooms with the potential to affect aquaculture operations. 
Figure 3. In coastal bays and fjords in Norway, blooms of Dinophysis produce recurrent contamination of shellfish by toxins associated with diarrhetic shellfish poisoning (DSP). The photograph shows reddish water produced by a massive bloom of the dinoflagellates Dinophysis spp. (about $2.5 \times 10^{7}$ cells/L) and Polykrikos sp. (about $1.1 \times 10^{7}$ cells $/ L$ ) in a very sheltered bay along the southern coast of Norway (29 September 1993). Data on the seasonal occurrence of Dinophysis acuminata, D. acuta and D. norvegica are presented for Flødevigen Bay, an exposed bay along the southern coast of Norway. Plankton samples are collected from the 0-3 m stratum three times per week for harmful algal monitoring. The bold black lines represent median values for each week from all data for the period 1989 to 2003; the dotted lines (bounding the redshaded area) indicate the first and third quartiles.

dies, in contrast to coastal embayments, such systems are hydrographically less stable and reproducible. Blooms originate from localized point sources, for example, excystment of benthic resting stages from the sediment, or from relict populations overwintering in the water column, often concentrated at density discontinuities such as the thermocline or the sediment-water interface. At least in the initial stages of the bloom development, this contributes to a very localized patchy distribution whereby the microstructure of the population cannot be adequately interpreted via a coarse sampling regime. A fundamental question for HAB dynamics related to life-history strategies is whether the bloom originates from resident endogenous populations within the embayment or via an inoculum transferred from the adjacent open coastal waters whereby the embayment does not act as a seed bed. If the blooms tend to originate from resident populations within the embayment, they are more likely to reappear on a cyclical (annual) basis because they are less dependent upon the vagaries of current patterns and other hydrographic variability along the outer coast for inoculation.

To borrow an analogy from labora-
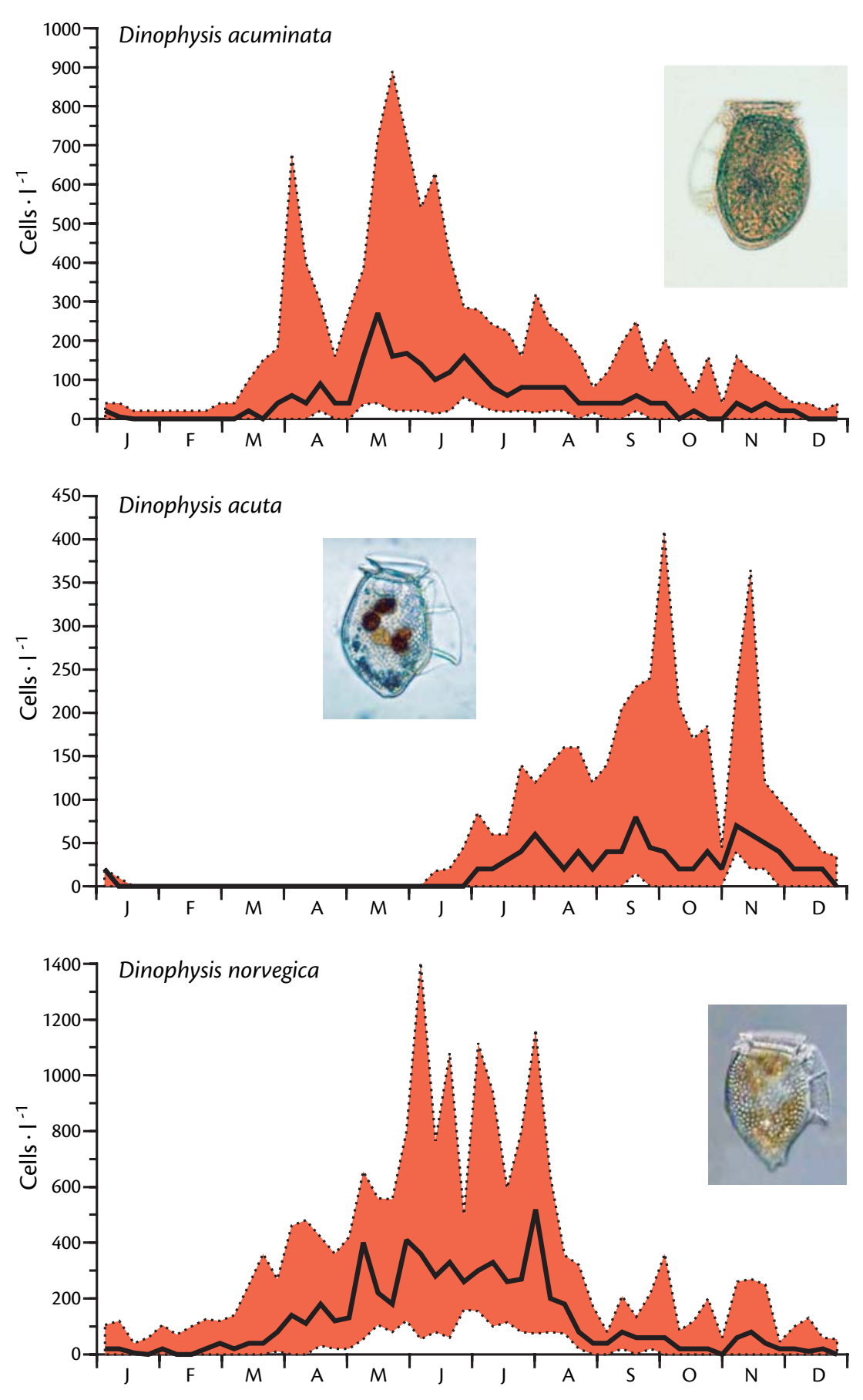
tory culturing of phytoplankton, if the flux of water and material to and from the embayment is extremely limited, the bloom may be operating in "batch culture" mode, whereas if the flux is substantial and periodic, the system may be described as in semi-continuous or continuous mode. In either case, such fluxes can be modeled as though the system were a large mesocosm. Studies of lifehistory dynamics, including benthic cyst mapping, measurement of in situ rates of encystment and excystment, and cyst advection, are often more tractable in these confined systems than in large open coastal regimes of unrestricted longshore transport. The ability to define and sample an appropriately fine spatio-temporal grid is extremely advantageous.

As retention zones, coastal embayments provide the opportunity for the expression of adaptive strategies that may be somewhat different than those expressed by similar HAB taxa along the outer coasts. This may include opportunistic response to rapid input of freshwater, macronutrients, and organic substances. The relative confinement of phytoplankton and zooplankton within embayments should also favor adaptations for allelochemical interactions among species (Cembella, 2003). Toxins leaked or excreted from algal blooms, particularly during senescence phase, may also have currently unrecognized ecological consequences.

Defining population genetics and adaptive responses are crucial to understanding dynamics of particular HAB taxa. Depending upon the degree of hydrodynamic and geomorphological isolation, coastal embayments may be suited to studies on biogeography, including genetic isolation and introduction and survival of exotic species.
Such studies are crucial to analysis of the global spreading hypothesis for HABs. Many of the key HAB taxa of interest, such as the dinoflagellates Alexandrium spp. and Dinophysis spp., responsible for paralytic- and diarrhetic- shellfish poisoning, respectively, and the diatom Pseudo-nitzschia spp., the cause of amnesic shellfish poisoning, are virtually identical in temperate coastal embayments of both the North and South hemispheres. For example, in the Americas, the chain-forming toxic species $\mathrm{Al}$ exandrium catenella occurs prominently in the fjordal systems of both British Columbia and Chile, whereas the non-chain forming A. tamarense is an important toxigenic component in coastal embayments in the northwest Atlantic (Gulf of St. Lawrence to the Gulf of Maine) and the southwest Atlantic (Argentine coast). These observations reflect a rather symmetrical biogeographical distribution.

In an apparent asymmetrical pattern, Alexandrium catenella is absent from the northwestern Atlantic, but occurs in embayments along the Mediterranean coasts of southern France and Catalonia. Alexandrium ostenfeldii, the source of spirolide toxicity, is common in Scandinavia and eastern Canada (Figure 4), where it co-occurs with A. tamarense, but the former species also appears in New Zealand.

Is the biogeographical distribution of Alexandrium species a reflection of latitudinal cosmopolitanism, species introduction, or common genetics of survivors within similar ecosystems? If the latter is the case, what are the features in common between Chilean fjords and Mediterranean embayments? An alternative hypothesis would be that the morpho-species definition of Alexandrium does not reflect hidden genetic diversity and adaptive strategies.
Empirical observations suggest that fish-killing microalgae, particularly naked dinoflagellates, raphidophytes, and prymnesiophytes, are prominent in enclosed and semi-enclosed coastal systems. To some extent, these observations may be an artifact of the tendency of many blooms of fish-killing species to be initiated and develop within general features of coastal circulation, for example, the association of species such as Karenia mikimotoi, Chrysochromulina polylepis, and Chattonella verruculosa with tidal fronts and coastal buoyant jets. Some of these populations then become trapped within fjords and other coastal embayments where the cell numbers and biomass increase and the expressed fish-killing properties are magnified and become apparent through devastation of marine resources.

In situ development of ichthyotoxic blooms within coastal embayments is also favored by the heavy influence of run-off from the adjacent land mass. For example, blooms of the ichthyotoxic prymnesiophyte Chrysochromulina may be promoted via the direct influence of nutrients and/or stratification (Edvardsen and Paasche, 1998). It is unclear if the correlation of such blooms with abundant freshwater input reflects a direct stimulatory response to low salinity, the consequent transport of macro-nutrients, a shift in nutrient supply ratios, the increased contribution of terriginous growth-promoting substances (e.g., natural chelators and vitamins), increased availability of organic nutrients for facultative heterotrophic species, the suppression of allelochemical effects, or merely the direct physical effect of freshwater in contributing to the stratification of the water column. Is this adaptive or merely a reflection of our focus on spe- 
cies that harm fisheries and aquaculture?

In coastal embayments in Japan, algae-killing bacteria have been implicated in the termination of raphidophyte blooms. These systems provide a useful model for studies on the global importance of bacteria and viruses in bloom termination. In addition, the importance of the microbial loop, which is often ignored in studies of HAB dynamics, can be addressed and quantified more easily in spatially confined ecosystems.

The role of pelagic grazers, particularly mixotrophic protists and metazooplankton is often acknowledged as a major factor regulating the dynamics of harmful plankton blooms-a form of "top-down" control (Granéli and Carlsson, 1998; Turner et al., 1998). Yet, the composition of the grazing community in coastal embayments, especially those dominated by abundant freshwater input and with restricted exchange with the open coast, is often remarkably different in time, space, and species composition to that found offshore. Tintinnids and other ciliates, rotifers, and euryhaline copepods are frequently the major phytoplankton predators in embayments. Even the species composition of the dominant copepods feeding upon harmful algae may be substantially different than on the outer coast. For example, in the Gulf of Maine, USA, the copepod Calanus finmarchicus is usually the dominant predator upon the toxic Alexandrium cells, whereas in bays and estuaries this role is assumed by other copepods, such as Acartia, Centropages and Eurytemora.

Benthic-pelagic coupling is undoubtedly more important in explaining $\mathrm{HAB}$ dynamics in coastal embayments than in open coastal or oceanic environments. This is partially related to the basin depth, but more importantly to the func-
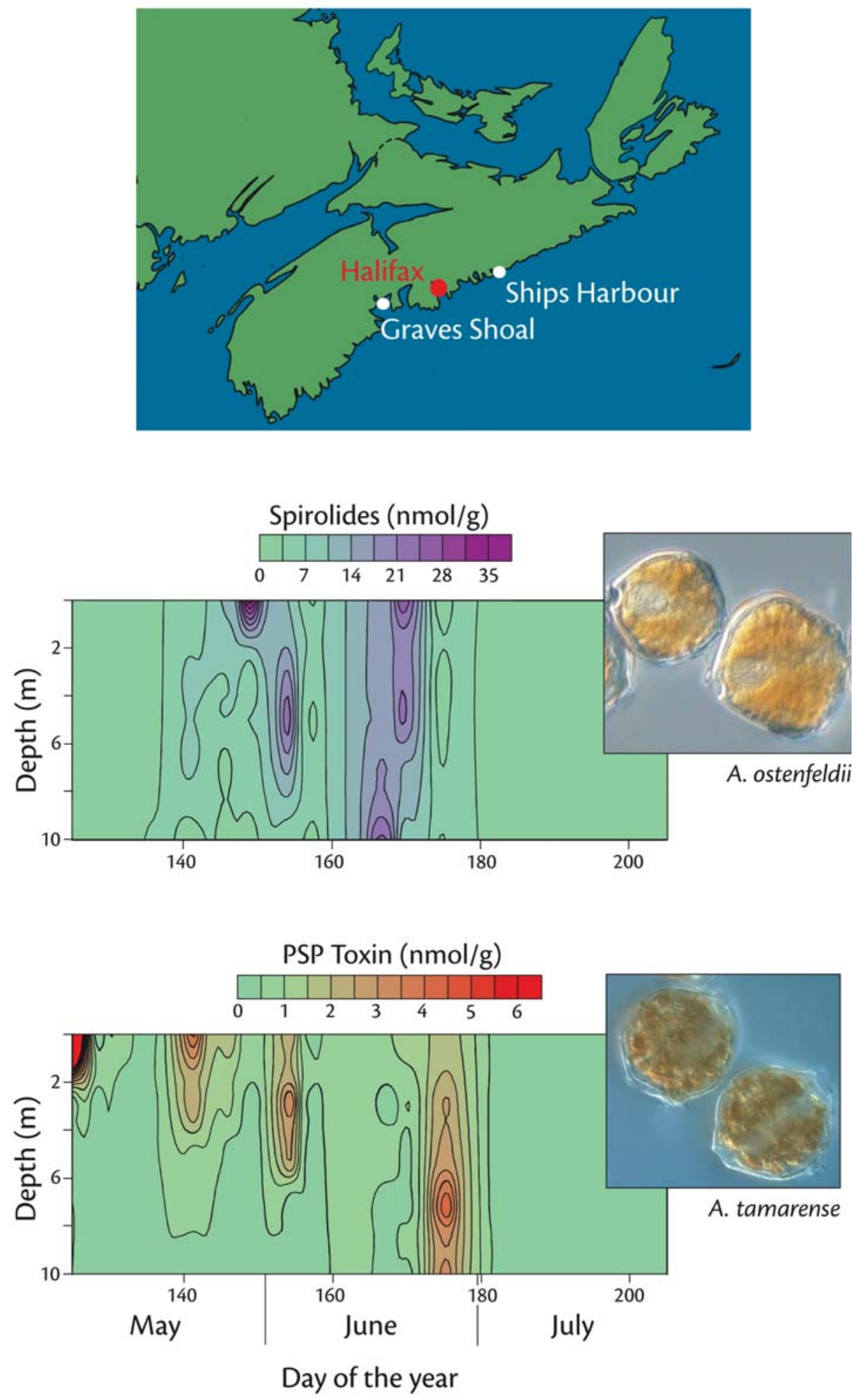

Figure 4. Several toxic dinoflagellate species form blooms within the coastal embayments of Nova Scotia. Shellfish toxicity at aquaculture sites is caused by Alexandrium tamarense, the species responsible for paralytic shellfish poisoning (PSP) and A. ostenfeldii, associated with spirolide toxicity. The spatio-temporal variation in particulate toxin concentration associated with the presence of blooms of these species in the water column at Graves Shoal, Nova Scotia are shown here. Note the differences in bloom dynamics reflected in the "patchiness" of these toxin groups in the water column over time. Assistance of Nancy Lewis and Michael Quilliam, IMB, National Research Council, Halifax for toxin analysis is gratefully acknowledged. 
tion of the benthos as a retention zone for resting cysts and as a substrate for colonization by epi-benthic species. In coastal embayments, particularly in shallow waters, beds of benthic macroalgae, sea grasses, and macro-fauna provide surfaces for attachment of harmful microalgal species. Benthic toxic dinoflagellates, such as species of the genera Prorocentrum, Coolia, Ostreopsis, and Gambierdiscus, are commonly found on these substrates (Tindall and Morton, 1998). Benthic substrates act as localized point sources for toxicity associated with ciguatera fish poisoning (CFP) in the tropics and sub-tropics and diarrhetic shellfish poisoning in temperate embayments.

The contribution of benthic grazers to the control of phytoplankton biomass and dynamics is enhanced in coastal embayments, particularly in shallow zones. Shellfish aquaculture through the water column from ropes, rafts, cages or longlines can further add to plankton depletion. Bivalve mollusks, including clams, mussels, scallops, and oysters, may even be dominant over pelagic grazers in such a system. This is in contrast to the situation in open coastal areas where benthic grazing is not nearly as important.

The study of bloom dynamics in relation to the hydrographic regime in coastal embayments is complex, but there are, nevertheless, significant advantages over similar studies in large coastal jet current or upwelling systems, in terms of determining cause-and-effect relationships. First, qualitative and quantitative time-series data of harmful algal species are often more readily available, along with a good basic understanding of the water circulation patterns. Second, point sources and fluxes of nutrients, toxic cells, seawater, and freshwater into the system can be more easily defined. Final- ly, the system can be exploited for data collection on a scale that closely matches that of the plankton patch size, thereby facilitating integration and interpretation of biological, chemical, and physical signals at the appropriate scale.

\section{DETECTION AND SURVEILLANCE OF BLOOMS IN COASTAL EMBAYMENTS}

Coastal embayments are character-

ized by high temporal and spatial biogeochemical variability, thus, HABs in these systems tend to be "patchy" in time and space. Studies of bloom dynamics must therefore incorporate instrument deployment for bloom detection and monitoring at the appropriate spatiotemporal resolution. The small spatial scale and relatively protected characteristics of coastal embayments permit detailed studies of the environmental regime and the community structure of plankton populations, often from small vessels (Figure 2), aircraft (Figure 5), or with the use of moored instrumentation (Figure 6). Bio-optical detection of HABs tends to be restricted to high-biomass bloom events, although some HAB species can cause negative effects at low biomass and without dominating the phytoplankton (Cullen and MacIntyre, 1998).

Bio-optical autonomous instruments are particularly well suited to assess biogeochemical variability at high temporal and vertical scales (Dickey and Moore, 2003). Comprehensive reviews of different bio-optical instruments and techniques to detect HABs are available (Cullen et al., 1997; Dickey, 2003). Here we focus only on techniques and methods that address the heterogeneity of phytoplankton at both temporal and spatial scales (Figure 6). There is increasing evidence that blooms that vary vertically within the water column (e.g., thin-layers) are particularly important in coastal embayments and may have profound implications on effectiveness for bloom detection.

Measurements that have the potential to detect HABs can be divided into three categories depending upon their vertical resolution: (1) single-depth measurements, where the measurement is representative of a unique narrow depth interval (e.g., a few centimeters); (2) depth-integrated measurements, where the measurement is representative of a larger depth interval (usually several meters); and (3) depth-resolved measurements, where multiple measurements (of a few centimeters to a few meters) throughout the water column provide resolution of the variability with respect to depth. These latter measurements can be obtained using instruments that produce single-depth or depth-integrated measurements, when deploying them on a vertical array or on a profiling platform. Alternatively, laser-induced fluorescence sensors produce depth-resolved measurements from surface installations or above-water (e.g., shipboard or airborne) systems.

\section{Single-Depth Measurements}

The most common measurements collected for studies of bloom dynamics in coastal embayments are single-depth measurements, for which equipment such as fluorometers and/or transmissometers are moored for varying lengths of time to resolve a specific question or as part of a routine bloom monitoring program.

The suite of single-depth measurements encompasses: (1) light absorption and attenuation, typically determined with commercially available in situ in- 
strumentation to measure absorption/attenuation/transmission of a thin beam of light over a defined path length; (2) backscattering of light, which cannot be measured directly, but various backscattering devices and the appropriate algorithms allow estimation of backscattering; and (3) field submersible fluorometers that measure in situ stimulated fluorescence, most commonly of chlorophyll $a$ and colored dissolved organic matter (CDOM). In the case of chlorophyll $a$, measurements must be interpreted with care because the fluorescence intensity per unit pigment is a physiological variable that is strongly affected by environmental conditions such as light or nutrient availability.

All above-mentioned instruments are equipped with their own source of light (i.e., active sensors). Therefore, measurements can be obtained at night and are independent of the ambient illumination (i.e., inherent optical properties); however, measurements of chlorophyll $a$ fluorescence are biased under exposure to sunlight. Disadvantages of singledepth measurements are that they have high power requirements and, most importantly, that they may completely fail to detect a phytoplankton bloom if the bloom occurs at a depth different from that of the sensor.

\section{Depth-Integrated Measurements}

The main depth-integrated measurements are: (1) remote-sensing reflectance, $R_{\mathrm{RS}}(\lambda)$, calculated as the ratio of upwelling radiance from the water to downwelling irradiance from the surface; (2) diffuse attenuation coefficient, $K_{d}(\lambda)$, a measure of the attenuation of light with depth calculated from downwelling irradiances measured at two depths; and (3) laser-induced fluorescence for the

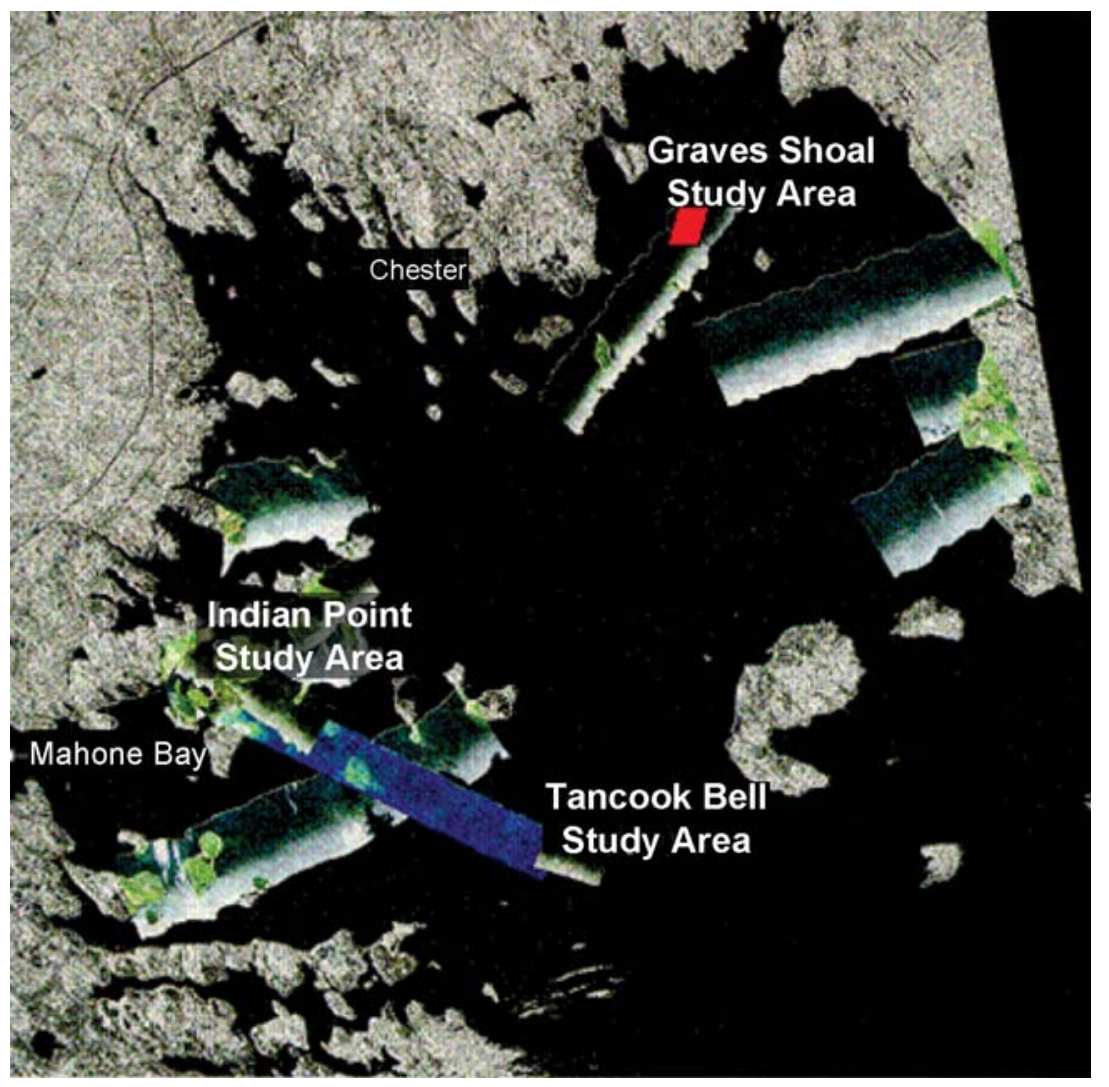

Figure 5. Coastal Embayment Study Area at Chester Basin, Graves Shoal, Mahone Bay. Graves Shoal is a shallow bank (depth 6 to $15 \mathrm{~m}$ ) within a much larger coastal embayment system, Chester Basin, along the southeastern shore of Nova Scotia, Canada. The embayment receives abundant freshwater, particularly in the late spring, but there is no single dominant point source inflow. Mahone Bay is linked to the open coast via numerous channels and is only semi-enclosed; therefore, the phytoplankton composition tends to be typical of the adjacent coastal waters. Phytoplankton is typically dominated by centric diatoms during the classic spring-bloom, and this is followed by a minor bloom of large thecate dinoflagellates, including toxic species, usually during May to July. Aircraft survey images shown here were collected by a Compact Airborne Spectographic Imager (CASI) system at $2 \mathrm{~m}$ and $4 \mathrm{~m}$ resolution. Data are displayed as a True Color Composite re-sampled to $6.25 \mathrm{~m}$ and integrated with RADARSAT FINE MODE F3 imagery. For scale, the red parallelogram at Graves Shoal indicates the location of a scallop aquaculture operation with an approximate surface area of $1 \mathrm{~km}^{2}$. Image processing and reproduction courtesy of Satlantic, Inc. measurement of bulk fluorescence of chlorophyll $a, \mathrm{CDOM}$, and other parameters of the upper water column. The first two measurements are derived from measurements of sunlight (i.e., from passive sensors) and therefore cannot be estimated at night. The third measurement uses a laser as a light source (i.e., active sensor) and can be estimated throughout day and night.
Measurements of remote-sensing reflectance and laser-induced fluorescence are typically obtained from satellites and airborne sensors, but they can also be provided continuously from autonomous buoys. The estimates of remotesensing reflectance and laser-induced fluorescence are restricted to surface layers because the contribution of deeper waters decreases logarithmically with 


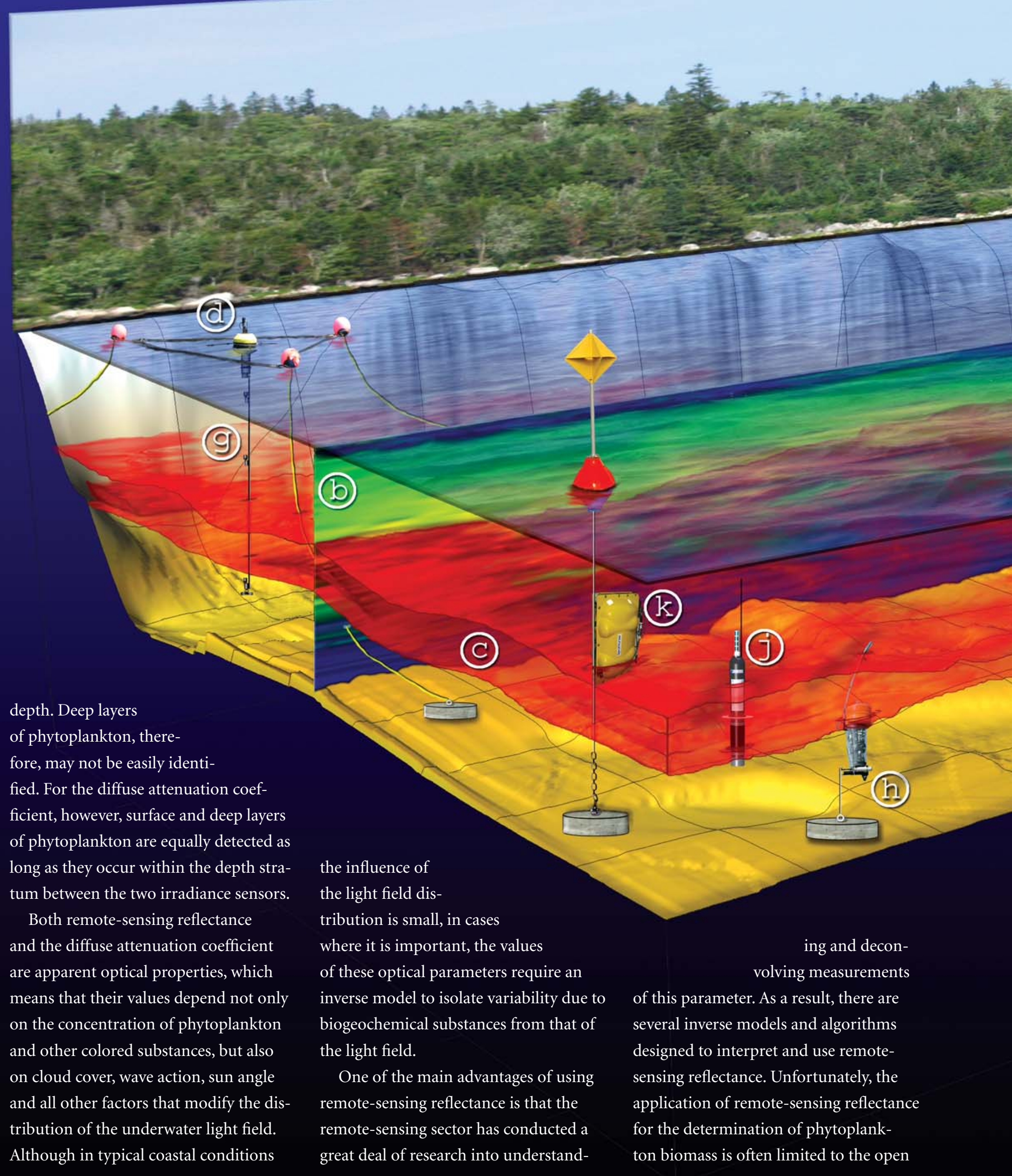




\section{Depth-Resolved Measurements}

Depth-resolved measurements are ob-

tained when one or more of the abovementioned sensors that produce sin-

gle-depth or depth-integrated measurements are mounted on a vertical array, a profiling platform, or are gated as in the case of laser-induced fluorescence sensors. Vertical arrays may be fixed with respect to the sea bottom or with respect to the sea surface (Figure $6 \mathrm{f}$ and $6 \mathrm{~g}$, respectively). Profiling platforms come in a variety of configurations ranging from: (1) winch profilers, where the winch can be located on a surface structure or attached to the instrument package as a submersible component; (2) wave-powered profilers, where the package free-floats to the surface and then it is propelled down a chain via wave energy transferred to a ratchet mounted on the instrument package; and (3) buoyancy-controlled profilers, where the changes in buoyancy generated by internal bladders cause the package to sink to the bottom or to float to the surface. Examples of these profiling devices have been developed for the open ocean, but they have not been used much in coastal embayments. Prototypes for coastal embayments may require tethering to the bottom to avoid drifting to shore or other conflict.

Devices that produce depth-resolved measurements are likely to be the most robust way to detect and assess phytoplankton blooms, including those of harmful species, in coastal embayments. Mounting an array with several instruments, however, can be very costly. Furthermore, profiling platforms are expensive, and systems with moving parts may require frequent maintenance and are more prone to failure. Yet, depending on the location of deployment, profiling de- vices may be sent via bidirectional communication to a safe depth for a certain time to avoid destruction due to, for example, hurricanes and sea ice (Cembella et al., 2004). Fixed, moored instruments are more likely to be destroyed during such events. In any case, depth-resolved systems have the advantage of producing more detailed information than is available from depth-integrated methods. For example, with depth-integrated systems, the presence of thin layers can be damped and thus not evident.

Single-depth measurements are not appropriate for the robust detection and assessment of HABs in fjords and coastal embayments. Future coastal systems for the continuous assessment of bio-geochemical variability and the detection of HABs may include a multimooring approach, where most of deployed moorings produce water-column integrated measurements and a few moorings are equipped with profiling devices for a more detailed description of the vertical structure.

\section{SUMMARY AND CONCLUSIONS}

A complete description of bloom dynamics in coastal embayments first requires establishing the hydrodynamics of the system, including a description of the following: (1) the basic horizontal circulation pattern; (2) the magnitude and frequency of exchange with outside waters; (3) the mechanisms of vertical stratification; and (4) the distribution of turbulent energy in response to the topography and external forcing (e.g., wind, freshwater, tides). The water column, or at least the depth of the euphotic zone, is very shallow in many coastal embayments. Vertical stratification of the water column is thus a critical feature determining the location and aggregation of HAB organisms.

In general, numerical models to define HAB dynamics should have a horizontal grid size small enough to adequately resolve one internal Rossby radius, preferably less than $1 \mathrm{~km}$. For operational and technical reasons (e.g., availability of ship time, cost of deployment of moorages, labor costs for sampling), it is often possible to conduct multiple modular comparative studies on bloom dynamics in coastal embayments that would not be feasible in larger coastal and oceanic systems. Nevertheless, the tendency for formation of thin layers requires highresolution measurements on the vertical axis and imposes large constraints on the use of instrumentation and the formulation of the physical processes for modeling at the appropriate scale.

Global climate change has been invoked (albeit speculatively) as a factor in the long-term development and spreading of HABs. Consideration of this hypothesis is particularly important because the effects of global change on marine ecosystems are likely to be first manifested and magnified within the coastal zone. The extent to which climate change affects the land-sea margins via sea-level rise, coastal erosion of retention zones, increased storm surges, decrease in ice cover, sediment transport, alteration of current patterns, and other geomorphological and hydrodynamic events may determine biogeography of certain $\mathrm{HAB}$ species and contribute to exogenous introduction in coastal embayments. Detailed monitoring of $\mathrm{HAB}$ species and the acquisition of time-series data within coastal embayments may elucidate effects of such changes in a rather conclusive manner over a relatively short-term 
(decadal) scale. By documenting the effects on harmful algal populations of perturbations within coastal embayments and fjords, cause-and-effect relationships may be established via hindcasting and forecasting models, with capability for testing hypotheses.

Within the international research framework of the GEOHAB (2001) program, a spectrum of coastal embayments representing different retention times and bathymetric characteristics are being established as pilot sites for detailed comparative studies on the physical, chemical, and biological factors that affect HABs. Comparative study of such systems will yield knowledge of the effects of benthicpelagic coupling on bloom dynamics and provide information for modeling changes in the coastal environment.

\section{ACKNOWLEDGEMENTS}

We thank the Intergovernmental Oceanographic Commission (IOC) and Scientific Committee on Oceanic Research (SCOR) for their generous financial and logistical support for the GEOHAB Open Science Meeting on HABs in Fjords and Coastal Embayments held on April 26-30, 2004 in Viña del Mar, Chile. Contributions from the program officers, Edward Urban (SCOR, Executive-Secretary) and Henrik Envoldsen (IOC-HAB program), as well as the Armada de Chile, and the local Chilean organizing committee are much appreciated. Much of the content of this article was developed following workshop discussions with the Core Research Project Coordinating Committee and attending members of the GEOHAB Scientific Steering Committee, including (in addition to the authors, Allan Cembella, Jorge Diogene, and Einar Dahl) Suzanne Roy (Canada), Robin
Raine (Ireland), Grant Pitcher (GEOHAB Chairman, South Africa), Patricia Glibert (USA), Bengt Karlson (Sweden), and Leonardo Guzman (Conference Co-convener, Chile). We further appreciate the excellent contributions to these discussions provided by those presenting plenary lectures on the key topics. שיd

\section{REFERENCES}

Anderson, D.M. 1998. Physiology and bloom dynamics of toxic Alexandrium species, with emphasis on life cycle transitions. Pp. 29-48 in Physiological Ecology of Harmful Algal Blooms. D.M. Anderson, A.D. Cembella and G.M. Hallegraeff, eds. NATO-Advanced Study Institute Series, V. 41. Springer-Verlag, Heidelberg, Germany. Brown, C.A., Y. Hout, M.J. Purcell, J.J. Cullen, and M.R. Lewis. 2004. Mapping coastal optical and biogeochemical variability using an Autonomous Underwater Vehicle (AUV) and new bio-optical inversion algorithm. Limnology and Oceanography: Methods 2:262-281.

Cembella, A.D. 2003. Chemical ecology of eukaryotic microalgae in marine ecosystems. Phycologia 42:420-447.

Cembella, B., H. Rohr, T. Witte, G. Buss, O. Zenk, and O. Zielinski. 2004. Integration of irradiance and radiance sensors in an autonomous profiling float. In: Proceedings of Ocean Optics XVII, Fremantle, Australia, October 25-29, 2004.

Cosper, E.M., V.M. Bricelj, and E.J. Carpenter. 1989. Novel Phytoplankton Blooms. Springer-Verlag, Berlin, Germany, 799 pp.

Cullen, J.J. and J.G. MacIntyre. 1998. Behavior, physiology and the niche of depth-regulating phytoplankton. Pp. 559-580 in Physiological Ecology of Harmful Algal Blooms, D.M. Anderson, A.D. Cembella and G.M. Hallegraeff, eds. NATOAdvanced Study Institute Series, V. 41. SpringerVerlag, Heidelberg, Germany.

Cullen, J.J., A.M. Ciotti, R.F. Davis, and M.R. Lewis. 1997. Optical detection and assessment of algal blooms. Limnology and Oceanography 42:12231239.

Dickey, T.D. 2003. Emerging ocean observations for interdisciplinary data assimilation systems. Journal of Marine Systems 40:5-48.

Dickey, T.D. and C. Moore. 2003. New sensors monitor bio-optical/biogeochemical ocean changes. Sea Technology, October.

Edvardsen, B. and E. Paasche. 1998. Bloom dynamics and physiology of Prymnesium and Chrysochromulina. Pp. 193-208 in Physiological Ecology of Harmful Algal Blooms, D.M. Anderson, A.D. Cembella and G.M. Hallegraeff, eds. NATO-Advanced Study Institute Series, V. 41. Springer-Ver- lag, Heidelberg, Germany.

GEOHAB. 2001. Global Ecology and Oceanography of Harmful Algal Blooms, Science Plan, P. Glibert and G. Pitcher, eds. Scientific Committee on Oceanic Research and Intergovernmental Oceanographic Commission, Baltimore and Paris, 86 pp.

Glibert, P.M., D.J. Conley, T.R. Fisher, L.W. Harding, Jr., and T.C. Malone. 1995. Dynamics of the 1990 winter/spring bloom in Chesapeake Bay. Marine Ecology Progress Series 122:27-43.

Granéli, E. and P. Carlsson. 1998. The ecological significance of phagotrophy in photosynthetic flagellates. Pp. 539-558 in Physiological Ecology of Harmful Algal Blooms, D.M. Anderson, A.D. Cembella and G.M. Hallegraeff, eds. NATO-Advanced Study Institute Series, V. 41. Springer-Verlag, Heidelberg, Germany.

Hargrave, B.T. 1991. Impact of Man's activities on aquatic systems. Pp. 245-264 in Fundamentals of Aquatic Ecology, 2nd ed., R.S.K. Barnes and K.H. Mann, eds. Blackwell Scientific, Oxford, U.K.

Riegman, R. 1998. Species composition of harmful algal blooms in relation to macronutrient dynamics. Pp. 475-488 in Physiological Ecology of Harmful Algal Blooms, D.M. Anderson, A.D. Cembella, and G.M. Hallegraeff, eds. NATO-Advanced Study Institute Series, V. 41. Springer-Verlag, Heidelberg, Germany.

Skjoldal, H.R., C. Hopkins, K.E. Erikstad, and H.P. Leinaas. 1995. Ecology of Fjords and Coastal Waters. Elsevier Science B.V., Amsterdam, The Netherlands.

Svendsen, H. 1995. Physical oceanography of coupled fjord-coast systems in northern Norway with special focus on frontal dynamics and tides. Pp. 49-164 in Ecology of Fjords and Coastal Waters, H.R. Skjoldal, C. Hopkins, K.E. Erikstad, and H.P. Leinaas, eds. Elsevier Science B.V., Amsterdam, The Netherlands.

Tindall, D.R. and S.L. Morton. 1998. Community dynamics and physiology of epiphytic/benthic dinoflagellates associated with ciguatera. Pp. 293-314 in Physiological Ecology of Harmful Algal Blooms. D.M. Anderson, A.D. Cembella and G.M. Hallegraeff, eds., Pp. 293-314. NATO-Advanced Study Institute Series, V. 41, Springer-Verlag, Heidelberg, Germany.

Turner, J.T., P.A. Tester, and P.J. Hansen. 1998. Interactions between toxic marine phytoplankton and metazoan and protistan grazers. Pp. 453474 in Physiological Ecology of Harmful Algal Blooms, D.M. Anderson, A.D. Cembella, and G.M. Hallegraeff, eds. NATO-Advanced Study Institute Series, V. 41. Springer-Verlag, Heidelberg, Germany.

Valiela, I. 1991. Ecology of coastal ecosystems. Pp. 57-76 in Fundamentals of Aquatic Ecology, 2nd ed., R.S.K. Barnes and K.H. Mann, eds. Blackwell Scientific, Oxford, U.K. 